\title{
Designing supply chains to meet the growing need of vaccines: evidence from four countries
}

\author{
Wendy Prosser ${ }^{*}$ (D, Cary Spisak, Benjamin Hatch, Joseph McCord, Marie Tien and Greg Roche
}

\begin{abstract}
Background: Immunization supply chains (iSCs) move vaccines from manufacturer to point of use with the added complexities of requiring cold chain and an increasing need for agility and efficiency to ensure vaccine quality and availability. Underperforming iSCs have been widely acknowledged as a key constraint to achieving high immunization coverage rates in low- and middle-income countries. This paper details the system design approach used to analyze the iSC network in Sierra Leone, Madagascar, Niger and Guinea and documents six lessons.

Methodology: Between 2018 and 2020, these countries implemented the system design approach, involving four key steps: (1) advocate and introduce to engage stakeholders and prioritize identification of modeling scenarios; (2) collect data and plan analysis through document review and key informant interviews; (3) analyze system design scenarios using computer software modeling tools (LLamasoft's Supply Chain Guru and AnyLogic's AnyLogistix) for optimization and simulation modeling as well as further analysis with Excel, Google maps, and OpenStreetMap; and (4) build consensus on optimized model and implementation roadmap using the Traffic Light Analysis tool and building on stakeholder input.
\end{abstract}

Findings: Key lessons include the following: (1) define system design objectives based on country priorities; (2) establish consensus with stakeholders on scenarios to model; (3) modeling provides the evidence but not the answer; (4) costs should not be weighted above other decision criteria; (5) data collection—work smarter, not harder; (6) not all questions can be answered with a computer model.

Discussion: A system design approach can identify changes to the design of the supply chain that can introduce efficiencies and improve reliability. This approach can be more effective when these lessons and principles are applied at the country level. The lessons from these four countries contribute to global thinking and best practices related to system design. The modeling and system design approach provides illustrative results to guide decision-makers. It does not give a "final answer", but compares and contrasts.

Keywords: Vaccine, Supply chain, System design

Communicated by Zaheer Babar, University of Huddersfield, UK

*Correspondence: wendy_prosser@jsi.com

John Snow, Incorporated, 2733 Crystal Drive, 4th Floor, Arlington, VA 22202, USA

\section{Background}

Public health supply chains move products from manufacturer to point of use through many distribution layers using various modes of transport and storage. Vaccines have the added complexity of requiring cold chain and more agility and efficiency to ensure product quality and availability. Underperforming immunization supply chains (iSC) have been widely acknowledged as a original author(s) and the source, provide a link to the Creative Commons licence, and indicate if changes were made. The images or other third party material in this article are included in the article's Creative Commons licence, unless indicated otherwise in a credit line to the material. If material is not included in the article's Creative Commons licence and your intended use is not permitted by statutory regulation or exceeds the permitted use, you will need to obtain permission directly from the copyright holder. To view a copy of this licence, visit http://creativecommons.org/licenses/by/4.0/. The Creative Commons Public Domain Dedication waiver (http://creativeco mmons.org/publicdomain/zero/1.0/) applies to the data made available in this article, unless otherwise stated in a credit line to the data. 
key constraint to achieving high immunization coverage rates in low- and middle-income countries [1, 2]. Many of these supply chains were designed more than 40 years ago, typically following administrative tiers, and now are considered outdated, inefficient, and unreliable. As a result, frequent stockouts hinder immunization coverage, excessive stock creates inefficiencies and waste, inaccurate forecasting can delay procurement and distribution, and non-functioning cold chain equipment (CCE) can diminish the quality of the vaccines.

As new vaccines are developed and immunization programs expand, there is ever-growing pressure to reduce wastage, improve efficiencies and reliability, and introduce agility to the iSC $[3,4]$. Considerable investments and efforts have been made to reach that goal. Many entities, in both the public and private sectors, have used a system design approach to analyze options to improve supply chain performance.

This paper details the system design approach for the iSC network and lessons learned in Sierra Leone, Madagascar, Niger, and Guinea. Results of the analysis have been published elsewhere [5]. The authors were hired to undertake a system design evaluation in each country, with the goal of identifying iSC bottlenecks, assisting stakeholders in identifying system design changes that might help remove these bottlenecks, and modeling these changes with network optimization software to advise on the likely outcomes of each possible system design change. The objective of this paper is to document six lessons from these four countries and the system design approach used to ensure evidence-driven, forward-looking decisions to improve supply chain performance.

\section{Methodology}

Between 2018 and 2020, these four countries implemented the system design approach (Fig. 1), which includes stakeholder engagement and the application of various modeling tools to quantitatively and qualitatively analyze the different components of the overall supply chain system and policies. The objective was to identify changes to component interaction to improve efficiency. The five-step approach allows stakeholders to evaluate different scenarios, pose "what if" questions, and measure the impact of proposed changes. The modeling results provide evidence that must be validated with stakeholders for a more informed decision on the iSC design [6-11] (Fig. 2). Each country undertook the following steps.

\section{Step 1: Advocate and introduce}

A broad stakeholder workshop in each country using case studies to demonstrate possible benefits ensured understanding of the system design approach. Participants included representatives from each level of the health system, from national to sub-national to health facility (HF) level. As the focus was on the iSC, immunization managers and logisticians were the key champions throughout this process; however, as integration with other supply chains was also being explored, representatives from Central Medical Stores (CMS) and other health programs also participated in some of the meetings. Other partners and funders involved in the supply chain, such as UNICEF; WHO; nongovernmental organizations; Gavi, the Vaccine Alliance; and USAID (in the case of Madagascar), were also involved.

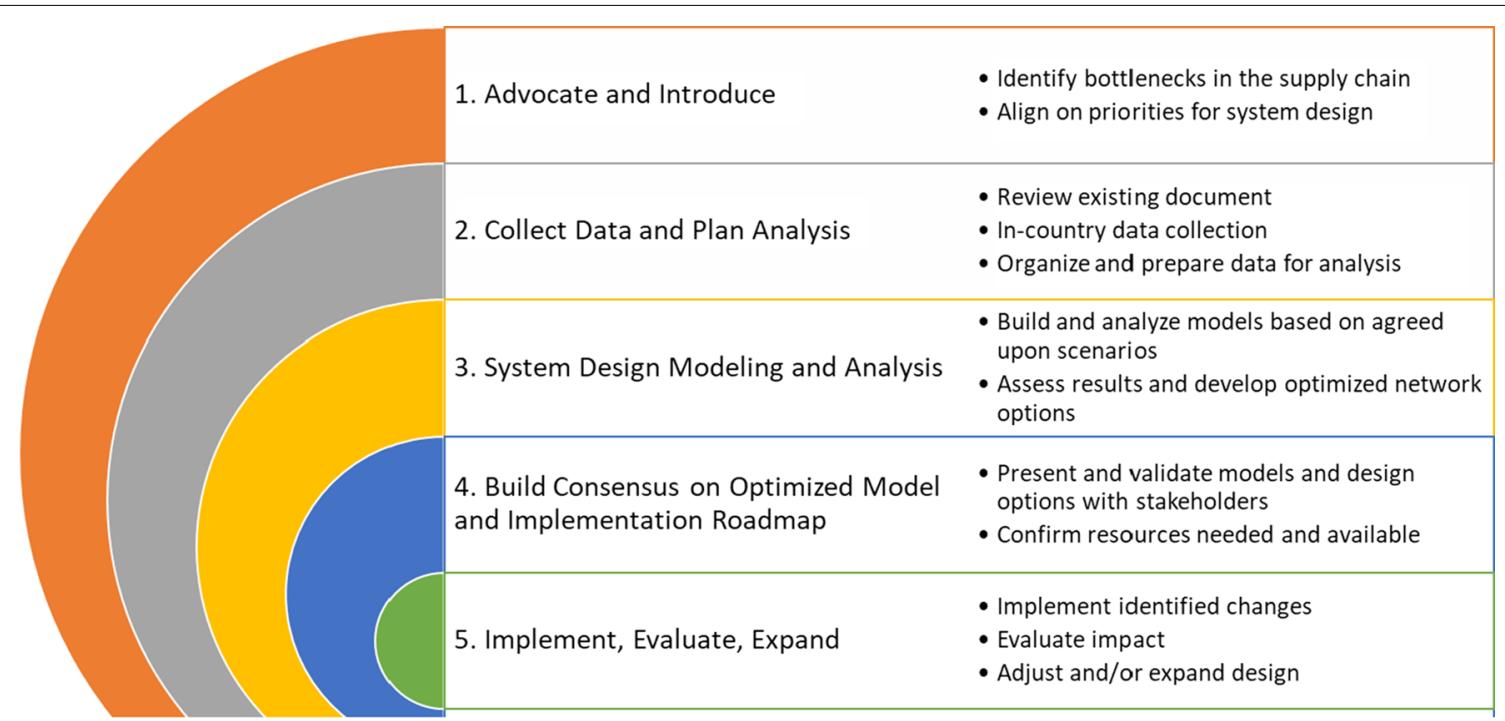

Fig. 1. The steps in a system design approach 


\begin{tabular}{|c|c|c|c|c|c|c|c|c|c|c|c|}
\hline Timeline & $\begin{array}{c}\text { Q2 } \\
2018\end{array}$ & $\begin{array}{c}\text { Q3 } \\
2018\end{array}$ & $\begin{array}{c}\text { Q4 } \\
2018\end{array}$ & $\begin{array}{c}\text { Q1 } \\
2019\end{array}$ & $\begin{array}{c}\text { Q2 } \\
2019\end{array}$ & $\begin{array}{c}\text { Q3 } \\
2019\end{array}$ & $\begin{array}{c}\text { Q4 } \\
2019\end{array}$ & $\begin{array}{c}\text { Q1 } \\
2020\end{array}$ & $\begin{array}{c}\text { Q2 } \\
2020\end{array}$ & $\begin{array}{c}\text { Q3 } \\
2020\end{array}$ & $\begin{array}{c}\text { Q4 } \\
2020\end{array}$ \\
\hline Sierra Leone & $\begin{array}{c}\text { Introduction } \\
\text { Workshop }\end{array}$ & & & & & $\begin{array}{c}\text { Data } \\
\text { Collection }\end{array}$ & $\begin{array}{c}\text { Modeling and } \\
\text { Analysis } \\
- \\
\text { Report Back } \\
\text {--- } \\
\text { Final Results }\end{array}$ & & & & \\
\hline Madagascar & & & & $\begin{array}{c}\text { Introduction } \\
\text { Workshop }\end{array}$ & & $\begin{array}{c}\text { Data } \\
\text { Collection }\end{array}$ & Report Back & $\begin{array}{c}\text { Final } \\
\text { Results }\end{array}$ & & & \\
\hline Niger & $\begin{array}{c}\text { Introduction } \\
\text { Workshop }\end{array}$ & & & & & & $\begin{array}{c}\text { Data } \\
\text { Collection }\end{array}$ & $\begin{array}{c}\text { Modeling } \\
\text { and } \\
\text { Analysis } \\
-- \text {-ort }^{-} \\
\text {Report Back }\end{array}$ & $\begin{array}{l}\text { Final } \\
\text { Results }\end{array}$ & & \\
\hline Guinea & & & $\begin{array}{l}\text { Introduction } \\
\text { Workshop }\end{array}$ & & & & $\begin{array}{c}\text { Data } \\
\text { Collection }\end{array}$ & $\begin{array}{c}\text { Data } \\
\text { Collection }\end{array}$ & & $\begin{array}{c}\text { Initial } \\
\text { Report } \\
\text { Back }\end{array}$ & $\begin{array}{c}\text { Final } \\
\text { Results }\end{array}$ \\
\hline
\end{tabular}

Fig. 2 Timeline for system design activities in four countries

A key workshop activity was to clearly identify known iSC bottlenecks, gaps, and strengths to identify distinct modeling scenarios that could mitigate bottlenecks and would be modeled under Step 3. The process involved a review of the country's immunization program, including program and supply chain performance and challenges. Through consensus building, participants agreed on a common definition of a highly performing supply chain as the ultimate goal of the system design approach. This approach provided a concrete foundation and a clear roadmap for next steps.

\section{Step 2: Collect data and plan analysis}

Categories of data needed include cost; human resources; network structure; CCE type, capacity, and location; and details on vaccines and consumables in the immunization schedule (Table 1). In Sierra Leone and Niger, additional information was collected on the estimated volume of oxytocin distributed to the facilities qualified to dispense the product to explore the possibility of integrating oxytocin into the vaccine cold chain. Additionally, scenarios exploring the use of autonomous aerial vehicles (AAVs) in Madagascar and Guinea required a number of assumptions on the AAV type, number required, payload capacity, location of AAV hubs, whether a third party

Table 1 Data required for modeling

\begin{tabular}{|c|c|}
\hline Cost & $\begin{array}{l}\text { Human resources: civil servant pay scale for health and warehouse staff } \\
\text { Vehicle: fixed purchase, capacity, fuel, operating expenses, number of facilities covered } \\
\text { per delivery } \\
\text { Public transportation: average cost per trip } \\
\text { Investment: building construction and CCE needed to set up a new location; addi- } \\
\text { tional vehicles for direct delivery, new routes; new technology (AAVs), training new/ } \\
\text { additional personnel } \\
\text { Operating and fixed storage } \\
\text { Maintenance and fuel for CCE } \\
\text { Straight line depreciation for vehicles and CCE }\end{array}$ \\
\hline Human resources & $\begin{array}{l}\text { Title, average number of staff, and time spent conducting logistics management tasks } \\
\text { Title, average number of staff at warehouse } \\
\text { Title, average number of staff who pickup/drop off commodities }\end{array}$ \\
\hline Network structure and facility data & $\begin{array}{l}\text { Number and location of all HF types that provide vaccines (with GIS coordinates) } \\
\text { Number and location of central, regional, district warehouses (with GIS coordinates) } \\
\text { Current delivery frequency/schedule for each supply chain level }\end{array}$ \\
\hline Cold chain equipment & Number, model, capacity, functional status of CCE at each HF or warehouse \\
\hline Vaccines and other commodities & $\begin{array}{l}\text { OVaccines for each location } \\
\text { OVolume for each location: } \\
\text { oTarget population } \\
\text { olmmunization schedule } \\
\text { oTarget coverage } \\
\text { ONew products for introduction or integration_-all of the above needed }\end{array}$ \\
\hline
\end{tabular}


or the ministry of health would manage the AAVs, and which facilities would receive them.

In each country, much of the data needed were available through existing sources such as the Cold Chain Equipment Inventory and Gap Analysis Tool, the EPI Logistics Forecasting Tool, and master facility lists. Additionally, a data collection tool was used in a sample of facilities and warehouses to collect information to build out and validate costing assumptions. In three countries, a stratified sample using the Central Limit Theorem guided the selection of facilities (urban/rural and harder to reach), visiting approximately two regions and 16-36 sites in each country. In Madagascar, a purposeful sample was used to ensure representation of the hardest-to-reach areas. Data collection through key informant interviews focused on estimating the average number of staff at each location, the hours spent on logistics tasks for vaccine management and picking up or delivering vaccines, the transportation normally used to collect or drop off commodities, and fixed and operating costs. Data collection also captured costs that are typically hidden from the central government, such as health workers paying out of pocket for public transportation to collect vaccines.

Stakeholders aligned on seven quantitative and qualitative key decision criteria that reflect the diverse aspects of supply chain performance and country priorities [12] (Fig. 3). Based on the results of the modeling, these criteria were analyzed for each scenario and compared to the baseline scenario.

\section{Step 3: Analyze system design scenarios using modeling} tools

Computer software modeling tools, namely LLamasoft's Supply Chain Guru and AnyLogic's AnyLogistix, were used for optimization and simulation modeling for the baseline of the current iSC and the scenarios chosen in each country. Optimization determines the lowest-cost constellation of current or theoretical resources, such as which facility should resupply from which warehouse, regardless of whether this constellation is possible with available resources. Simulation modeling, on the other hand, applies real-world conditions, such as constraints in the number of trucks and truck driver working hours that are not addressed by optimization [13]. The level of detail-such as facility and warehouse locations, CCE capacity, transportation, and warehousing costs per kilometer traveled or per cubic centimeter of product handled-necessary for the different supply chain scenarios is built into the model to evaluate the effects of policy or structural changes in terms of total system costs, costs per vaccine dose delivered, and volume throughput for each warehouse and HF. Additional analyses using Excel, Google maps, and OpenStreetMap were used to address aspects not directly included in the modeled scenarios, such as estimating the number of vehicles needed for different scenarios, cold chain capacity use, and change in the number of staff hours when shifting to direct delivery. For the

\begin{tabular}{|c|c|c|c|}
\hline & Indicator & Definition & Analysis \\
\hline \multirow{3}{*}{ 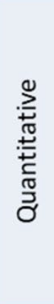 } & Total supply chain cost & $\begin{array}{l}\text { All operational costs (warehouse, } \\
\text { transport, HR for inventory } \\
\text { management) }\end{array}$ & $\begin{array}{l}\text { Positive effect: reduced overall } \\
\text { costs }\end{array}$ \\
\hline & Cost per dose delivered & $\begin{array}{l}\text { Total supply chain costs divided by all } \\
\text { vaccines distributed }\end{array}$ & $\begin{array}{l}\text { Positive effect: reduced cost } \\
\text { per dose }\end{array}$ \\
\hline & $\begin{array}{l}\text { Cold Chain Equipment } \\
\text { (CCE) Capacity }\end{array}$ & Sufficient for quantities delivered & $\begin{array}{l}\text { Positive effect: sufficient CCE } \\
\text { capacity }\end{array}$ \\
\hline \multirow{4}{*}{ 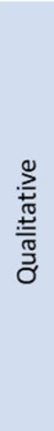 } & $\begin{array}{l}\text { Logistics burden on health } \\
\text { worker }\end{array}$ & $\begin{array}{l}\text { Health worker has to fetch vaccines, } \\
\text { health center closes }\end{array}$ & $\begin{array}{l}\text { Positive effect: Less travel time } \\
\text { per health worker, fewer } \\
\text { health center closures }\end{array}$ \\
\hline & Feasibility & $\begin{array}{l}\text { Political will for change, } \\
\text { implementation, resources }\end{array}$ & $\begin{array}{l}\text { Positive effect: reflects financial } \\
\text { and political support }\end{array}$ \\
\hline & Risk of mishandling & $\begin{array}{l}\text { Risks related to extra time in the } \\
\text { supply chain, many touch points }\end{array}$ & $\begin{array}{l}\text { Positive effect: reduced travel } \\
\text { time, reduced touch points }\end{array}$ \\
\hline & Equity & $\begin{array}{l}\text { CCE availability, distance of population } \\
\text { to health facility, distance to resupply } \\
\text { points }\end{array}$ & $\begin{array}{l}\text { Positive effect: reduced travel } \\
\text { time and/or distance, sufficient } \\
\text { CCE availability }\end{array}$ \\
\hline
\end{tabular}

Fig. 3 Decision criteria used for analysis 
purpose of this activity, all of these types of analysis fall under the broader term "modeling."

\section{Step 4: Build consensus on optimized model and implementation roadmap}

Results were presented to stakeholders using the Traffic Light Analysis Tool to assess the change in the indicators for each of the scenarios compared to the baseline scenario (Fig. 4). Green, yellow, and red symbols are used for each criteria to indicate a positive, limited, or negative effect, respectively. Each modeled scenario is evaluated in terms of quantitative changes (such as change in system cost or cost per dose delivered) and qualitative indicators (such as difficulty of implementation or equity considerations, defined as the change in the logistics burden placed on last-mile HFs). Qualitative indicators were evaluated under the traffic light scheme based on the appreciation of the project team (for example, changing distribution from quarterly to monthly for a system that requires lastmile HFs to travel to pick up their vaccines implies an increase in the logistics burden on those facilities and therefore a negative effect on equity overall; the equity indicator in this scenario would be labeled as red). At a final report-back workshop, stakeholders reviewed modeling results and agreed on priorities for implementation.

\section{Step 5: Implement, evaluate, and expand}

This step involves implementing changes identified by the modeling and agreed upon by stakeholders. It was out of this activity's scope.

\section{Findings}

From this process emerged six key lessons that can be applied in other countries adopting a system design approach.

\section{Lesson 1: Define system design objectives based on country priorities}

Based on the initial identification of bottlenecks and gaps in performance, stakeholders identified a few common priorities with the ultimate goal of improving immunization coverage rates that resonated across the four countries (Table 2). Stakeholders prioritized reducing operating costs and creating an efficient, equitable, and sustainable system. Any changes to the iSC should ensure immunization availability, particularly at last-mile HFs. Improving availability and use of CCE was another common theme. Finally, integration, either the "low-hanging fruit" of non-vaccine cold chain products such as oxytocin being included in the vaccine cold chain or the fullscale integration of vaccines into CMS was a common priority for three of the four countries.

Sierra Leone stakeholders prioritized reducing the burden on health workers through direct delivery to HFs and were interested in considering different vial sizes to reduce missed opportunities for vaccination [14]. Stakeholders in Madagascar, Niger, and Guinea prioritized data availability for decision-making and were each closely exploring options for a fully integrated public health supply chain.

\section{Lesson 2: Establish consensus with stakeholders on scenarios to model}

Stakeholders identified scenarios that reflected best practices in supply chain management while adapting to country context. Stakeholders in all four countries

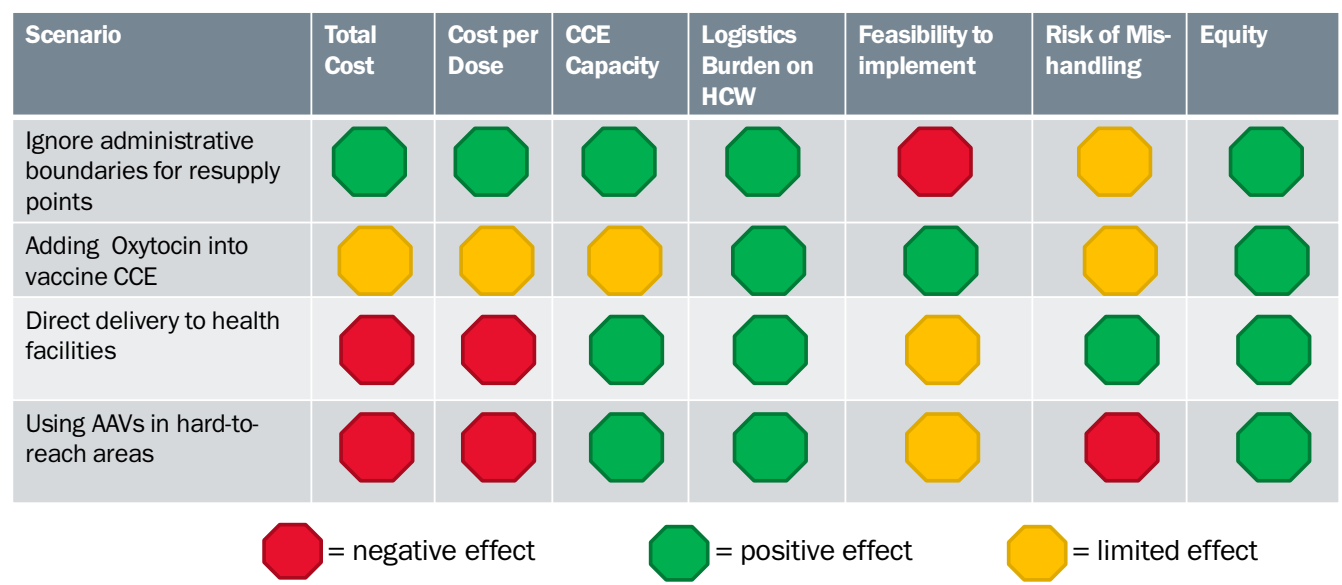

Fig. 4 Sample of traffic light analysis tool 
Table 2 Country-identified bottlenecks in the current iSC and priorities for the system design approach

\begin{tabular}{|c|c|}
\hline Bottlenecks & Priority \\
\hline \multicolumn{2}{|l|}{ Sierra Leone } \\
\hline $\begin{array}{l}\text { Inadequate workload balance } \\
\text { Additional skills building needed } \\
\text { Forecasts do not match consumption } \\
\text { Insufficient funds for distribution }\end{array}$ & $\begin{array}{l}\text { Ensure availability of vaccines to all children } \\
\text { Reduce operating costs/improve cost effectiveness } \\
\text { Ensure CCE at all (or at least } 80 \% \text { of) HFs } \\
\text { Optimize storage space } \\
\text { Integrate with other cold chain products } \\
\text { Consider different vaccine vial presentations } \\
\text { Reach underserved/hard-to-reach areas (equity) } \\
\text { Reduce time spent in logistics } \\
\text { Guarantee distribution from district to HF } \\
\text { Optimize district/regional stores and their linked } \\
\text { network/transport routes } \\
\text { Suptimize transport system for district distribution and } \\
\text { supervision }\end{array}$ \\
\hline \multicolumn{2}{|l|}{ Niger } \\
\hline $\begin{array}{l}\text { Insufficient transport, particularly at sub-national levels } \\
\text { Security challenges in conflict-prone areas } \\
\text { Human resource (HR) constraints in availability and skills }\end{array}$ & $\begin{array}{l}\text { Achieve a more reliable system } \\
\text { Guarantee regular delivery of vaccines to the last mile } \\
\text { Ensure quality of vaccines in sufficient quantity } \\
\text { Optimize use of CCE } \\
\text { Base supply chain decisions on actual data } \\
\text { Integrate management system with qualified staff }\end{array}$ \\
\hline \multicolumn{2}{|l|}{ Madagascar } \\
\hline $\begin{array}{l}\text { Failure to use the regional administrative level for the iSC } \\
\text { Unused regional cold rooms } \\
\text { Antiquated facility-level CCE depend on propane tanks } \\
\text { Inadequate funds and insufficient vehicles to support distribution } \\
\text { Insufficient HR for iSC management } \\
\text { Ad hoc district distribution to HFs }\end{array}$ & $\begin{array}{l}\text { Ensure an effective, equitable, and adaptable system } \\
\text { Provide reliable data } \\
\text { Reduce operating costs } \\
\text { Increase immunization coverage } \\
\text { Reduce expired vaccines } \\
\text { Promote sustainability } \\
\text { Upgrade CCE }\end{array}$ \\
\hline \multicolumn{2}{|l|}{ Guinea } \\
\hline $\begin{array}{l}\text { Lack of cold chain at regional level } \\
\text { Insufficient cold chain capacity at districts and HFs } \\
\text { Insufficient means of transport } \\
\text { Insufficient HR capacity for CCE maintenance } \\
\text { Inadequate budgeting and planning based on inaccurate population estimates }\end{array}$ & $\begin{array}{l}\text { Ensure an effective, equitable, and adaptable system } \\
\text { Provide reliable data through computerized system } \\
\text { Introduce cost savings } \\
\text { Promote sustainability } \\
\text { Decentralize to ensure all products are available at HF } \\
\text { Integrate and provide high-quality services } \\
\text { Ensure availability of CCE at all levels } \\
\text { Allocate qualified and sufficient HR } \\
\text { Establish regional cold chain depots }\end{array}$ \\
\hline
\end{tabular}

explored different delivery frequencies to sub-national stores and facilities (shifting to delivery to HFs every 2 months or quarterly instead of monthly) to optimize cold chain storage and transport. Stakeholders in Madagascar, Guinea, and Sierra Leone considered changing resupply points that ignore administrative boundaries to allow HFs to collect or receive vaccines from district resupply points to which they may not report administratively but that are geographically closer, thereby reducing travel time and costs. This reflects a private sector logistics company best practice.

Stakeholders in all four countries were interested in adjusting the number of supply chain layers, either by adding regional levels (to be more in-line with the administrative structure, as in Madagascar and Guinea) or by removing a layer to reduce the number of touch-points in the supply chain (Sierra Leone, Niger, and a variation of a scenario in Guinea). Removing a layer of the supply chain often reduces costs, decreases the time a product spends in the supply chain, and increases product availability [15]. In Guinea, Niger, and Sierra Leone there was also interest in direct delivery from the last resupply point at the district level to the HF to reduce health workers' logistics burden of vaccine collection.

The final two common themes in the scenarios reflect the new AAV technology and the global push for supply chain integration. AAVs were included as a scenario in Madagascar and Guinea; interestingly, they were discussed in Niger, but ultimately not included as a scenario because AAVs would not be acceptable for use in the country's high-risk security areas. Stakeholders in three countries considered some aspects of integration, with Sierra Leone and Niger most interested in including other cold chain products in the vaccine supply chain, 
and full integration of vaccines into the CMS considered in Guinea and Niger. This interest in integration in Guinea and Niger also reflects the broad mandate and goal of the CMS in each of these countries, as well as external donor interest.

The importance of having participants identify clear and well-understood scenarios while considering the implications on administrative and start-up costs, HR, potential risks, and political will cannot be understated.

\section{Lesson 3: Modeling provides the evidence but not the answer}

Modeling is a tool to weigh the benefits and drawbacks of a complex set of trade-offs and interdependencies among the many components of the supply chain design. It helps evaluate the performance of the various supply chain strategies without having to invest in those changes preemptively [16, 17].

There are limits to modeling. The results of modeling can serve as evidence for answering the "what if" questions; however, the "what's best" question must still be answered by stakeholders who understand the results of modeling and can place it in the reality of the country context. For example, ignoring administrative boundaries to adjust resupply points for shorter travel distance will reduce operating costs, but the political will to make that change may require significant advocacy and coordination, as noted in Sierra Leone. Additionally, this type of change has implications for health system reporting and supervision structures, administrative policies, and forecasting processes, which cannot be modeled. In short, some changes may be feasible but would require stakeholder input, guidance, and applying common sense to the results of the analysis.

Understanding the possibilities and limits of modeling at the beginning of the system design approach can maximize this approach to identify scenarios that are realistic and produce useful results from the analysis.

\section{Lesson 4: Costs should not be weighted above other decision criteria}

The Traffic Light Analysis tool proved to be an effective way to communicate information on the effects of the different scenarios on all of the identified criteria, while full details of the analysis were provided during the report-back workshop for a more in-depth understanding of the potential changes and requirements. The tool emphasizes the importance of considering both quantitative and qualitative key decision criteria for scenario assessment. While the qualitative criteria are somewhat subjective, they are no less important. For example, the equity criteria depend greatly on the country context yet also reflect the global importance of equity in the supply chain and for immunization coverage $[18,19]$.

It is also important to link the results analysis to the purposes and priorities of the system design approach as determined by stakeholders during the first step of this approach. For example, some scenarios may have higher operational costs, but support the priority of reducing the vaccine collection burden on health workers. Using this set of criteria helps weigh the trade-offs of design choices and contributes to reaching consensus for prioritizing actions.

\section{Lesson 5: Data collection-work smarter, not harder}

It is not practical or necessary to visit every HF or distribution point in a country to collect primary data from every individual involved in supply chain management. Primary data collected from a sample of facilities and distribution points provide sufficient insight to create generalized cost assumptions to apply across each country model. Stakeholders validated the appropriateness of these cost assumptions during assumption-validation meetings. The key is that because individual costs will vary not only across hundreds or thousands of HFs, but also over time, it is impractical to collect detailed cost data for each point in the supply chain. However, if a small sample can provide cost estimates that are close to correct on average, the resulting model can still help identify the likely results of structural changes to a supply chain. The modeling results therefore provide a high-level overview (such as total supply chain costs) or answers that are "directionally consistent" (i.e., the approach can show which design yields cost increases, but not necessarily the exact expected costs) with insight into some details (such as specific CCE with constraints).

Several challenges emerged during data collection and cleaning. First, inconsistency across different datasets related to facility names and spelling required a significant level of cleaning and matching to create a reliable master list of facilities with their corresponding CCE, locations, and catchment populations. A standardized master facility list for the ministry of health would be beneficial to this approach, but such standardization did not exist in any of the four countries included in this analysis. Secondly, as the system is dynamic, information changes regularly and datasets become outdated quickly. This was particularly true for the CCE inventory as each country was receiving new equipment during the same time period that these analyses were being conducted, and even the number of facilities was changing as facilities opened and closed. 


\section{Lesson 6: Not all questions can be answered} with a computer model

Modeling can analyze the complex interplay among many supply chain components and provide insight into how changes can affect supply chain performance. Modeling is best used to determine potential changes in the characteristics and flow of products, and to identify storage locations and needs, transport needs and optimal routes, and inventory needs. Beyond these, modeling can provide indications of $H R$ needs, information management systems and data flow requirements, and equity considerations for vaccine availability, but further and different analyses are required for more precise estimates for these and other aspects of the supply chain.

In the four countries, stakeholders identified a wide range of priorities for the iSC to address with system design and modeling, some of which would need separate analysis and planning. In Madagascar, Guinea, and Niger, stakeholders set the goal of a reliable data-driven supply chain. This is best achieved through a well-functioning logistics management information system and structured data review teams [20]. However, the impact of those components and how well they are managed cannot be captured in a supply chain model. Human resources is another important component of the supply chain, but fully understanding HR needs requires a workforce assessment complemented by a capacity-building strategy to close any gaps. A final example is immunization coverage. Vaccine availability is a requirement for immunization coverage, yet many other factors-accessibility to an HF, caregiver knowledge, financial resources, migration patterns, and even trust in the immunization program and health system-affect a child's ability to get vaccinated [21]. A computer model can identify the truck and warehouse capacities and optimal delivery frequencies, but only a caregiver can determine if a child arrives at an HF to receive a vaccine.

Additionally, computer modeling cannot determine total actual current supply chain costs. Results of the modeling analysis provide estimated total operating costs and costs per dose delivered within each of the different scenarios; however, these do not reflect financially accurate costs that a costing assessment can provide. In Madagascar, an initial supply chain costing exercise was conducted and the results used to build the supply chain model and contribute to the system design analysis. A costing assessment can identify cost drivers and gaps in funding for specific segments or components of the supply chain, and provide evidence for advocating and planning for funding [22].

\section{Discussion}

A system design approach can identify changes to the design of the supply chain that can introduce efficiencies and improve reliability. The lessons from these four countries contribute to the global thinking and best practices related to system design and its applicability at the country level. As a core principle, stakeholder engagement and consensus building set the foundation for this approach and aligned priorities. This is particularly important as some of these priorities may be inherently conflicting [12]. For example, ensuring direct delivery from the districts to HFs inevitably will introduce incremental costs borne by the district government, compared to a system that uses an ad hoc approach that largely depends on health workers collecting vaccines (and often paying out of pocket for transport). However, it may also contribute to the ultimate goal of improving immunization coverage rates while reducing the burden on the health worker. The system design approach helps weigh the trade-offs with both quantitative and qualitative decision criteria.

Another core principle is selecting scenarios that are considered feasible. Although tools can model many scenarios, only some can be implemented due to resource constraints, policies, and even in-country politics. Scenarios can ask the "what if" questions, but they must reflect the real-world context [23]. For example, integration of vaccines into the CMS is considered a way to improve efficiency [24], but it must be managed appropriately and can often be challenging to get political will for such a significant change in management and product flow. The results from the modeling exercise may provide evidence that will garner the needed political will, or, depending on the country context, be of no help at all.

A limitation of this study is that it does not follow the fifth step of change implementation. While it provides the evidence for change, it remains to be seen how or if stakeholders will advance any changes to the supply chain design. While many of the scenarios present innovative ideas, implementing change will require using the evidence from the system design approach to advocate with key decision-makers.

It is important to note that system design provides illustrative results to guide decision-makers. It does not give a "final answer" but compares and contrasts the trade-offs between the various scenarios. Despite the quantitative evidence gained from modeling, common sense and understanding of the country context must be the basis of system design analysis. Available evidence can inform decision-making to achieve better-performing supply chains. 


\section{Acknowledgements}

We thank the Ministry of Health and the leaders of the immunization program in Sierra Leone, Madagascar, Niger and Guinea for their continued support for this activity and commitment to improving the performance of the immunization supply chain. We also thank the many supply chain managers and logisticians who contributed to the system design process and their belief in making a difference. In each country, UNICEF was instrumental in engaging key stakeholders and contributing to the process. For that we are thankful.

\section{Authors' contributions}

WP and CS conceived of, designed, and oversaw the system design activity. WP, CS, BH, and MT contributed substantially in the development of the analysis approach, data collection, and data cleaning. CS, BH, JM, and MT conducted the analysis and preparation of the final results. GR, BH and CS were instrumental in stakeholder engagement and reporting back results for alignment and priority setting. All authors contributed to the interpretation, discussion and writing of the manuscript. All authors read and approved the final manuscript.

\section{Funding}

The system design analysis in Sierra Leone was financially support by UNICEF/ Sierra Leone, contract \#43273626. The activities in Madagascar, Guinea and Niger were funded by Gavi, the Vaccine Alliance, contract CP 88430520. Neither funder had any role in the design, analysis or writing of this paper or in the decision to submit the paper for publication.

\section{Availability of data and materials}

The data, data collection tools, analysis and other materials can be obtained from the corresponding author.

\section{Declarations}

\section{Ethics approval and consent to participate}

Ethics approval was not required as the information used for the analysis was freely available in the public domain. The study did not involve or use human subjects or identifiable personal data. The analysis was implemented with the permission of and in collaboration with the Ministry of Health, and all information was kept anonymous. All authors have read and agreed to its content and are accountable for all aspects of the accuracy and integrity of the manuscript.

\section{Consent for publication}

The authors declare that the article is original, has not already been published in another journal, and is not currently under consideration by another journal.

\section{Competing interests}

The authors declare no competing interests.

Received: 21 June 2021 Accepted: 17 September 2021 Published online: 29 September 2021

\section{References}

1. Vouking MZ, Mengue CMA, Yauba S, Edengue JM, Dicko M, Dicko HM, et al. Interventions to increase the distribution of vaccines in Sub-Saharan Africa: a scoping review. Pan Afr Med. 2019. https://doi.org/10.11604/ pamj.2019.32.14.17225.

2. World Health Organization, UNICEF. Effective vaccine management (EVM) global data analysis 2009-2018 report. Geneva: World Health Organization; 2018. p. 57.

3. Rao R, Schreiber B, Lee BY. Immunization supply chains: why they matter and how they are changing. Vaccine. 2017;35(17):2103-4. https://doi.org/ 10.1016/j.vaccine.2017.02.062

4. Duijzer LE, van Jaarsveld W, Dekker R. Literature review: the vaccine supply chain. Eur J Oper Res. 2018;268(1):174-92. https://doi.org/10.1016/j. ejor.2018.01.015.
5. Prosser W, Folorunso O, McCord J, Roche G, Tien M, Hatch B, Spisak C, Genovese E, Pare B, Donatien K, Ibrahim M, Abou-Charaf E, Wright C, Dubourg JC. Redesigning immunization supply chains: results from three country analyses. Vaccine. 2021. https://doi.org/10.1016/j.vaccine.2021. 03.037.

6. Huang XX, Guillermet E, Le Gargasson JB, Alfa DA, Gbodja R, Sossou AJ, et al. Costing analysis and anthropological assessment of the vaccine supply chain system redesign in the Comé District (Benin). Vaccine. 2017;35(17):2183-8. https://doi.org/10.1016/j.vaccine.2016.12.075.

7. Lee BY, Mueller LE, Tilchin CG. A systems approach to vaccine decision making. Vaccine. 2017. https://doi.org/10.1016/j.vaccine.2016.11.033.

8. Prosser W, Jaillard P, Assy E, Brown ST, Matsinhe G, Dekoun M, et al. System redesign of the immunization supply chain: experiences from Benin and Mozambique. Vaccine. 2017;35(17):2162-6. https://doi.org/10.1016/j.vacci ne.2016.09.073.

9. Lee BY, Haidari LA, Prosser W, Connor DL, Bechtel R, Dipuve A, et al. Redesigning the Mozambique vaccine supply chain to improve access to vaccines. Vaccine. 2016;34(41):4998-5004. https://doi.org/10.1016/j.vacci ne.2016.08.036.

10. Sarley D, Mahmud M, Idris J, Osunkiyesi M, Dibosa-Osadolor O, Okebukola P, et al. Transforming vaccines supply chains in Nigeria. Vaccine. 2017;35(17):2167-74. https://doi.org/10.1016/j.vaccine.2016.11.068.

11. Lee BY, Schreiber B, Wateska AR, Connor DL, Dicko HM, Jaillard P, et al. The Benin experience: how computational modeling can assist major vaccine policy changes in low and middle income countries. Vaccine. 2015;33(25):2858-61. https://doi.org/10.1016/j.vaccine.2015.04.022.

12. Decouttere $C$, Vandaele $N$, Lemmens S, Bernuzzi M. The vaccine supply chain multathlon: the reconciliation of technology, economy and access to medicines. In: Zobel CW, Altay N, Haselkorn MP, editors. Advances in managing humanitarian operations. Switzerland: Springer International Publishing; 2015. p. 205-27 (10.1007/978-3-319-24418-1_10).

13. Ingalls R. Introduction to supply chain simulation. Proceedings of the 2014 Winter Simulation Conference. 2014. https://informs-sim.org/wsc14 papers/includes/files/006.pdf. Accessed 12 Aug 2020.

14. Krudwig K, Knittel B, Karim A, Kanagat N, Prosser W, Phiri G, et al. The effects of switching from 10 to 5 -dose vials of MR vaccine on vaccination coverage and wastage: a mixed-method study in Zambia. Vaccine. 2020;38(37):5905-13. https://doi.org/10.1016/j.vaccine.2020.07.012.

15. Assi TM, Brown ST, Kone S, Norman BA, Djibo A, Connor DL, et al. Removing the regional level from the Niger vaccine supply chain. Vaccine. 2013;31(26):2828-34. https://doi.org/10.1016/j.vaccine.2013.04.011.

16. Informed design: how modeling can provide insights to improve vaccine supply chains. (n.d.). VillageReach. https://www.villagereach.org/wpcontent/uploads/2017/10/ModelingOverview_Final.pdf. Accessed 8 Aug 2020.

17. Martínez-Olvera C, Davizon-Castillo YA. (2015). Modeling the supply chain management creation of value-a literature review of relevant concepts. In: Tozan H, Ertuk A. Applications of contemporary management approaches in supply chains. https://doi.org/10.5772/59656

18. Considering Equity in Vaccine Supply Chains. VillageReach. (n.d.). https:// www.villagereach.org/considering-equity-in-vaccine-supply-chains/. Accessed 16 Aug 2020.

19. Zameer M, Phillips-White N, Folorunso O, Belt R, Setayesh H, Asghar N, Chandio A. Promoting equity in immunization coverage through supply chain design in Pakistan. Gates Open Res. 2020. https://doi.org/10.12688/ gatesopenres.13121.1.

20. Data Review Teams: A Promising Practice to Improve Data Use and Strengthen Immunization Supply Chains. 2019. https://www.technet-21. org/media/com_resources/trl/5621/multi_upload/Data\%20Review\% 20Teams\%20for\%20iSC\%20Strengthening_Synthesis\%20Report_20191568230736.pdf. Accessed 24 Aug 2020.

21. Bangura JB, Xiao S, Qiu D, Ouyang F, Chen L. Barriers to childhood immunization in sub-Saharan Africa: a systematic review. BMC Public Health. 2020;20(1):1108. https://doi.org/10.1186/s12889-020-09169-4.

22. The Right Cost: Analyzing Public Health Supply Chain Costs for Sustainability. (2013). USAID|DELIVER. 2013. https://publications.jsi.com/JSIIn 
ternet/Inc/Common/_download_pub.cfm?id=16936\&lid=3. Accessed 16 Aug 2020.

23. Min H, Zhou G. Supply chain modeling: past, present and future. Comput Ind Eng. 2002;43(1-2):231-49. https://doi.org/10.1016/S0360-8352(02) 00066-9.

24. Yadav P, Lydon P, Oswald J, Dicko M, Zaffran M. Integration of vaccine supply chains with other health commodity supply chains: a framework for decision making. Vaccine. 2014;32(50):6725-32. https://doi.org/10. 1016/j.vaccine.2014.10.001

\section{Publisher's Note}

Springer Nature remains neutral with regard to jurisdictional claims in published maps and institutional affiliations.
Ready to submit your research? Choose BMC and benefit from:

- fast, convenient online submission

- thorough peer review by experienced researchers in your field

- rapid publication on acceptance

- support for research data, including large and complex data types

- gold Open Access which fosters wider collaboration and increased citations

- maximum visibility for your research: over 100M website views per year

At BMC, research is always in progress.

Learn more biomedcentral.com/submissions 